\title{
My favorite person
}

I forget sometimes that you are not the person I once knew. And I say something the way I used to quick, without context, off the cuff things that the person I once knew would catch without fail and respond NOT with a 'what?' and a frown nor with a 'I have no idea what you're talking about' but with a wink and a smile, because you got it.

You got me without the subtext.

But that was then.

And I sometimes forget that this is now.

You are still my favorite person

but now, I need to catch your attention before I speak

To give reference to context - because you will have forgotten.

I need to speak clearly and slowly

and wait for the spark to light in your eyes

- or not -

before I add more words to the cacophony

that is roaring in your head.

Or is it the silence that deafens you?

You won't tell me,

or you can't.

But you're still my favorite person,

And I try really hard,

but sometimes I forget

and then we have a day like today

with you cross and resentful at something

that I didn't tell you the moment it happened

- like you expected me to -

except that I did, but you've forgotten....

so when I speak without context

when I speak without reminding you

the light in your eyes sparks once, furious,

then dies into sullen indifference -

only because I forgot that you're not the person I once knew -

quick and sharp and funny and trusting -

even though you're still my favorite person.

\section{Upreet Dhaliwal}

Correspondence to Upreet Dhaliwal, Director Professor of Ophthalmology, and Member, Medical Humanities Group, University College of Medical Sciences, University of Delhi, India; upreetdhaliwal@yahoo.com

Competing interests None declared.

Provenance and peer review Not commissioned; internally peer reviewed.

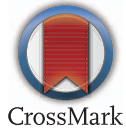

To cite Dhaliwal U. Med Humanit 2017:43:e21.

Published Online First 3 February 2017

Med Humanit 2017:43:e21. doi:10.1136/medhum-2016-011182 